\title{
Efficient solvent-free synthesis of pyridopyrazine and quinoxaline derivatives using copper-DiAmSar complex anchored on SBA-15 as a reusable catalyst
}

\author{
Marzieh Mohammadi a, Ghasem Rezanejade Bardajee ${ }^{b, *}$, Nader Noroozi Pesyan ${ }^{a}$ \\ a Department of Chemistry, Faculty of Science, Urmia University, 57159, Urmia, Iran \\ ${ }^{b}$ Department of Chemistry, Payame Noor University, P.O. BOX, 19395-3697, Tehran, Iran
}

\section{A R T I C L E I N F O}

Article history:

Received 14 February 2015

Accepted 17 March 2015

Published 20 August 2015

Keywords:

DiAmSar

SBA-15

Heterogeneous catalyst

Pyridopyrazine

Quinoxaline

\section{A B S T R A C T}

A catalytic system comprising mesoporous silica functionalized with $\mathrm{Cu}(\mathrm{II})$-DiAmSar was synthesized. This was demonstrated as an efficient heterogeneous catalyst for the synthesis of biologically useful pyridopyrazine and quinoxaline heterocycles under solvent-free conditions. X-ray diffraction, transmission electron microscopy, $\mathrm{N}_{2}$ adsorption-desorption, Fourtier transformation infrared spectroscopy, and thermogravimetric analysis were used to characterize the catalyst and investigate the texture of SBA-15 during the grafting process.

(C) 2015, Dalian Institute of Chemical Physics, Chinese Academy of Sciences. Published by Elsevier B.V. All rights reserved.

\section{Introduction}

Natural and synthetic quinoxalines and their derivatives are well-known for their biological activities, including antiviral, antibacterial, anti-inflammatory, antiprotozoal, and kinase inhibitor behavior [1,2]. There are many pharmaceutical drugs such as Varenicline $\mathbf{1}$ (aid in smoking cessation), Brimonidine $\mathbf{2}$ (antiglaucoma activity), and Quinacillin 3 (antibacterial properties) that contain quinoxaline cores (Fig. 1) [3-5]. Thus, there is still a need for the development of a new, convenient, and environmentally benign synthesis approach.

In recent years, the heterogenization of homogenous catalysts has attracted attention because this overcomes several disadvantages such as tedious purification of the product and undesired wastewater produced in homogeneous base-catalyzed processes. Furthermore, many homogeneous systems consist of a metal and ligands in a particular stoichiometric ratio, and the removal of the ligands makes the purification of the product even more expensive. The design and development of new types of heterogeneous catalysts can mitigate these problems as it allows the straightforward removal of the catalyst from the reaction system.

Mesoporous silica has recently gained considerable attention in organic synthesis under heterogeneous reaction conditions, but they are not often used as catalysts. The surface functionalization of mesoporous silica by grafting or cocondensation is a promising approach for preparing efficient solid base catalysts. This method provides a way to attach catalytic centers onto mesoporous silica and avoids metal ion leaching [6-10]. Various silica supports like the M41S materials and SBA families with pore sizes between 2 and $50 \mathrm{~nm}$ have received attention in catalysis due to their high surface area (up

\footnotetext{
* Corresponding author. Tel: +98-28-33336366; Fax: +98-28-33344081; E-mail: rezanejad@pnu.ac.ir This work was supported by Payame Noor University. 


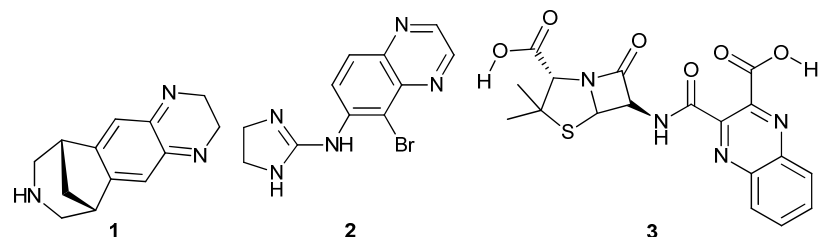

Fig. 1. Drug products that contain quinoxaline cores.

to $1200 \mathrm{~m}^{2} / \mathrm{g}$ ), uniform and tunable pore size, organic solvent tolerance, and large diversity in surface functionalization [11-13]. SBA-15 is the most well-known representative of this class of materials with good hydrothermal stability, hexagonal arrays of uniform pores with a high specific surface area, sufficient silanol groups for surface modification, and large pore volume that facilitates the grafting of homogeneous metal compounds through coordinative linkage [14-16].

Nowadays, organic-inorganic hybrids are of great interest because they combine the advantages of heterogeneous catalysts (high mechanical, thermal, and structural stability) and organic molecules (flexibility and functionality) $[17,18]$. We have focused on the synthesis of some heterogeneous organometallic catalysts and applied them in organic synthesis [19-23]. Here we report the application of a novel heterogeneous catalyst for the synthesis of biologically active pyrido[2,3-b]pyrazine and quinoxaline heterocycles under solvent-free conditions. The procedure for the preparation of the heterogeneous nanocatalyst is described in Schemes 1 and 2 [24]. The catalyst consists of DiAmSar ligands 7 (hexaminemacrobicyclic cage amine ligands which are known by their trivial name, sarcophagines, Scheme 1). This not only forms remarkably stable complexes with transition metal ions such as $\mathrm{Cu}$ (II), but also have fast complexation kinetics even at a low concentration of metal ions $[25,26]$. So this catalytic system has virtually no Cu-leaching. DiAmSar-based ligands are also appropriate for the encapsulation of radioisotope metal ions. They can conjugate to peptides, antibodies, and biologically compatible polymers by their amine functional groups, so they can be radio-labelled with PET (diagnostic positron emission tomography) isotopes for the imaging of molecular interactions [27-30].

To prepare the title heterogeneous catalyst, $\mathrm{Cu}(\mathrm{II})$-DiAmSar complex was anchored onto the SBA-15 mesoporous material.

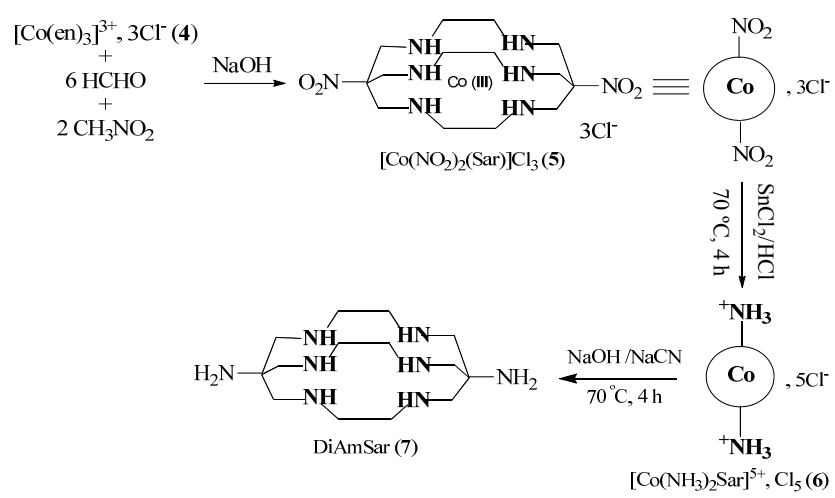

Scheme 1. Preparation of DiAmSar.

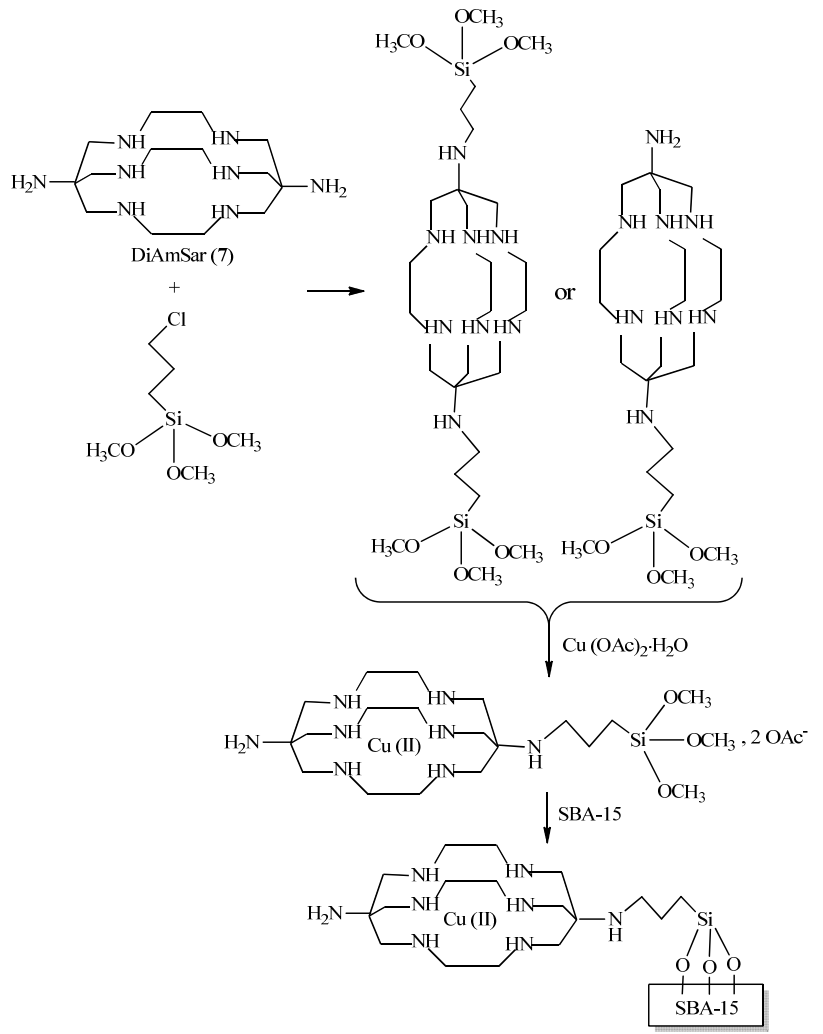

Scheme 2. Preparation of $\mathrm{Cu}(\mathrm{II})$-DiAmSar complex anchored on SBA-15 (Cu(II)-DiAmSar/SBA-15).

(3-Chloropropyl)trimethoxysilane reacted with the DiAmSar's amine functionality, complexed with the $\mathrm{Cu}(\mathrm{II})$ salt and was covalently immobilized on SBA-15 through the trimethoxysilane moiety (Scheme 2).

\section{Experimental}

\subsection{Materials}

Acetonitrile, ethanol, formaldehyde, $\mathrm{NaOH}$, methanol, stannous chloride dihydrate, $\mathrm{CoCl}_{2} \cdot 6 \mathrm{H}_{2} \mathrm{O}$, sodium cyanide, nitromethane, ethylanediamine, commercial 1,2-phenylenediamines, 2,3-diaminopyridine, 3,4-diaminopyridine, 1,2-dicarbonyl compounds, poly(ethylene oxide)-block-poly(propylene oxide)-block-poly(ethylene oxide) triblock copolymer (P123), (3-chloropropyl)trimethoxysilane (CPTMS), copper (II) acetate monohydrate, tetraethyl orthosilicate (TEOS), $\mathrm{HNO}_{3}$, and $\mathrm{HCl}$ were purchased from Sigma-Aldrich, Merck, and Acros chemical companies. Doubly distilled water was used when necessary. All materials were used without further purification. The solvents used for the synthesis were analytical grade and were used as received. Silica gel (Merck, grade 9385, 230-400 mesh, $60 \AA$ A) for column chromatography was used as received. All other reagents were purchased from Merck and used as received unless otherwise noted. The course of the synthesis of the heterocycle was followed by TLC on a silica gel plate (Merck, silica gel $60 \mathrm{~F}_{254}$, ready-use) using methanol (9:1) or $n$-hexane:ethyl acetate (1:3) as eluent. The eluent for column chromatography was the same as the TLC eluent. 


\subsection{Characterization}

Transmission electron microscopy (TEM) observation was performed with a Hitachi H-700 CTEM. Fourier transformation infrared (FT-IR) spectra were recorded using $\mathrm{KBr}$ pellets on a Jasco 4200 FT-IR spectrophotometer. X-ray diffraction (XRD; Bruker D8ADVANCE with Ni-filtered $\mathrm{Cu} K_{\alpha}$ radiation at 1.5406 $\AA$ ) was carried out with a speed of $2^{\circ} / \mathrm{min}$ and a step of $0.05^{\circ}$. ${ }^{1} \mathrm{H}$ and ${ }^{13} \mathrm{C}$ NMR spectra were recorded at room temperature on Bruker $\mathrm{AC} 300$ and $500 \mathrm{MHz}$ spectrometers using $\mathrm{CDCl}_{3}$ or DMSO- $\mathrm{d}_{6}$ as the NMR solvent. ${ }^{1} \mathrm{H}$ NMR spectra were referenced to tetramethylsilane $(0.00 \mathrm{ppm})$, and ${ }^{13} \mathrm{C}$ NMR spectra were referenced from the solvent central peak (for example, 77.23 ppm for $\mathrm{CDCl}_{3}$ ). Chemical shifts are given in ppm. $\mathrm{N}_{2}$ adsorption-desorption isotherms were obtained at $-196{ }^{\circ} \mathrm{C}$ with a Quantachrome Autosorb-1 apparatus. Before measurement, the sample was outgassed at $120^{\circ} \mathrm{C}$ for $12 \mathrm{~h}$. The specific surface area and pore size distribution were obtained from the desorption branch of the isotherm using the BET method and BJH analysis, respectively. A Shimadzu AA-6300 flame atomic absorption spectrometer was used to get the concentration of metal ions. For this purpose, $0.1 \mathrm{~g}$ of the catalyst was digested by $\mathrm{HNO}_{3}$ with stirring at room temperature for a week. Then the mixture was filtered and the solid was washed several times with water to get a colourless filtrate solution for metal measurement. The concentration of $\mathrm{Cu}$ (II) in the immobilized SBA-15 was $0.016 \mathrm{mmol} / \mathrm{g}$. Thermogravimetric analysis (TGA) was carried out with a TGA/DTA Shimadzu-50 instrument equipped with a platinum pan. The sample was heated in air from 25 to $1000{ }^{\circ} \mathrm{C}$ with a heating rate of $10{ }^{\circ} \mathrm{C} / \mathrm{min}$. The weight loss was recorded as a function of temperature. Melting points were recorded using a Buchi B540 melting point apparatus and were uncorrected.
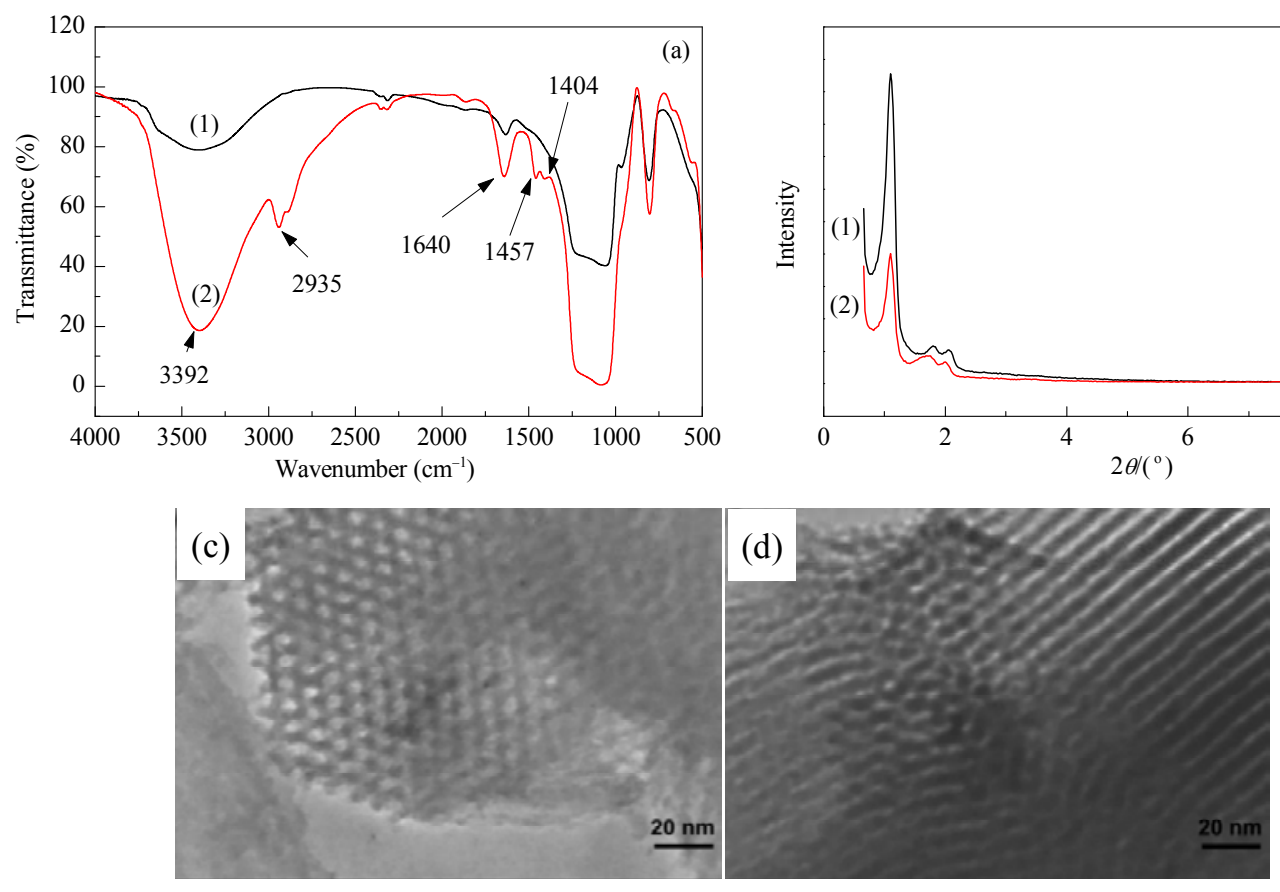

Fig. 2. (a) FT-IR spectra of SBA-15 (1) and Cu(II)-DiAmSar/SBA-15 (2). (b) XRD patterns of SBA-15 (1) and Cu(II)-DiAmSar/SBA-15(2). (c,d) TEM images of $\mathrm{Cu}(\mathrm{II})$-DiAmSar/SBA-15. (c) in the direction of the pore axis; (d) in the perpendicular direction to the pore axis.

2.3. General procedure for the synthesis of pyrazine-based heterocycles under solvent-free conditions

A round-bottomed flask equipped with a magnet and condenser was charged with the desired 1,2-diamine (1.0 mmol), 1,2-diketone (1.0 mmol), and catalyst (Cu(II)DiAmSar/SBA-15, $0.005 \mathrm{~g}$ ). The resulting mixture was heated at $100{ }^{\circ} \mathrm{C}$ for the appropriate time. The course of the reaction was monitored using TLC on silica gel. Finally, the reaction mixture was cooled, and the crude mixture was purified by column chromatography or crystallization to get the desired product. Spectral and physical data for all heterocycles were compared with reference samples and were in accord with previously reported data.

Selected spectroscopic data for compounds $10 \mathrm{v}$ and $10 \mathrm{w}$ were as follows.

8-Methyl-8,9-dihydro-acenaphtho[1,2-b]pyrazine 10v. Yield 98\%; yellow solid, $\mathrm{mp}: 73-75^{\circ} \mathrm{C}$. IR (KBr) $v\left(\mathrm{~cm}^{-1}\right): 3010,2929$, 1680, 1492, 1121. ${ }^{1} \mathrm{H}$ NMR (300 MHz, $\left.\mathrm{CDCl}_{3}\right) \delta 1.45(\mathrm{~d}, J=7.1$ $\mathrm{Hz}, 3 \mathrm{H}$ ), 3.54 (dd, $J=11.1 \mathrm{~Hz}, 6.0 \mathrm{~Hz}, 1 \mathrm{H}), 3.84-3.92(\mathrm{~m}, 1 \mathrm{H})$, $4.06(\mathrm{dd}, J=10.9 \mathrm{~Hz}, 6.1 \mathrm{~Hz}, 1 \mathrm{H}), 7.65(\mathrm{t}, J=7.5 \mathrm{~Hz}, 2 \mathrm{H})$, 7.89-7.95 (m, 4H). $\left.{ }^{13} \mathrm{C} \mathrm{NMR} \mathrm{(75} \mathrm{MHz,} \mathrm{CDCl}_{3}\right) \delta 158.3,157.9$, 141.6, 131.7, 131.5, 130.6, 128.4, 128.2, 127.8, 118.7, 118.6, 51.8, 49.7, 20.2. Anal. Calcd. for $\mathrm{C}_{15} \mathrm{H}_{12} \mathrm{~N}_{2}$ (220.2): C, 81.79; $\mathrm{H}$, 5.49; N, 12.72. Found: C, 81.68; H, 5.35; N, 12.59 .

2-Methyl-dibenzo[f,h]quinoxaline 10w. Yield 80\%; white solid, mp: $121-123{ }^{\circ} \mathrm{C}$. IR (KBr) $v\left(\mathrm{~cm}^{-1}\right): 3018,2920,1610$, $1501,1212 .{ }^{1} \mathrm{H} \mathrm{NMR}\left(300 \mathrm{MHz}, \mathrm{CDCl}_{3}\right) \delta 2.84(\mathrm{~s}, 1 \mathrm{H}), 7.71-7.80$ $(\mathrm{m}, 4 \mathrm{H}), 8.62(\mathrm{~d}, J=7.5 \mathrm{~Hz}, 2 \mathrm{H}), 8.77(\mathrm{~s}, 1 \mathrm{H}), 9.18(\mathrm{~d}, J=8.1 \mathrm{~Hz}$, $1 \mathrm{H}), 9.26(\mathrm{~d}, J=7.5 \mathrm{~Hz}, 1 \mathrm{H}) .{ }^{13} \mathrm{C}$ NMR $\left(75 \mathrm{MHz}, \mathrm{CDCl}_{3}\right) \delta: 152.6$, $143.8,140.2,138.7,131.4,130.9,130.0,129.9,129.2,128.9$, 128.4, 127.6, 127.5, 125.3, 124.9, 122.6, 22.2. Anal. Calcd. for $\mathrm{C}_{17} \mathrm{H}_{12} \mathrm{~N}_{2}$ (244.2): C, 83.58; H, 4.95; N, 11.47. Found: C, 83.65; H, 4.82; N, 11.30 .

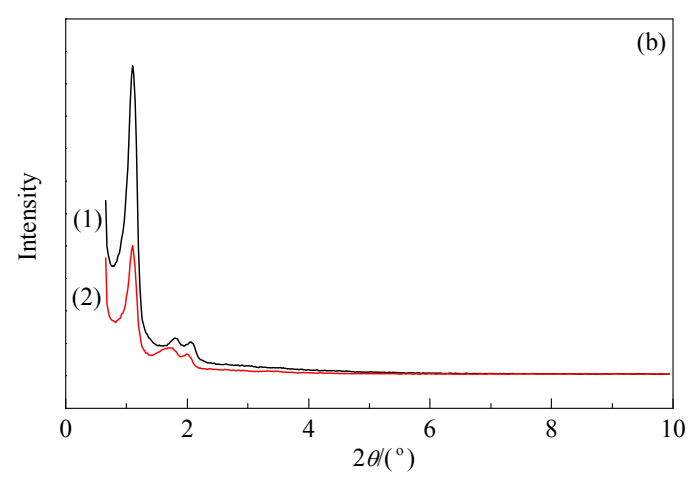




\section{Results and discussion}

\subsection{Characterization of Cu(II)-DiAmSar complex anchored onto $S B A-15$}

The successful grafting of the $\mathrm{Cu}(\mathrm{II})$-DiAmSar complex onto SBA-15 was characterized using various physico-chemical techniques. The FT-IR spectra of SBA-15 and Cu(II)-DiAmSar/ SBA-15 are shown in Fig. 2(a). Cu(II)-DiAmSar/SBA-15 showed both the silica framework and DiAmSar complex characteristic bands, including a strong absorbing band at 1000-1200 $\mathrm{cm}^{-1}$ (stretching vibration of the $\mathrm{Si}-\mathrm{O}-\mathrm{Si}$ bond), a broad band between 3000 and $3600 \mathrm{~cm}^{-1}$ (stretching vibration of $\mathrm{NH}$ (from DiAmSar) and OH (from SBA-15) groups), a peak at $1640 \mathrm{~cm}^{-1}$ (bending of the NH group), a medium band observed at 2955 $\mathrm{cm}^{-1}$ (stretching vibration of $\mathrm{CH}_{2}$ ), and peaks at 1400-1500 $\mathrm{cm}^{-1}$ (absorption peaks of $\mathrm{C}-\mathrm{N}$ groups).

The quality and structural ordering of $\mathrm{Cu}(\mathrm{II})$-DiAmSar/ SBA-15 were determined by XRD. The XRD patterns of both SBA-15 and Cu(II)-DiAmSar/SBA-15 (Fig. 2(b)) exhibited an intense peak at $1.1^{\circ}$ corresponding to the (100) reflection, and two low intensity peaks at $1.72^{\circ}$ and $1.98^{\circ}$ that were indexed as the (110) and (200) reflections. These peaks are from the ordered hexagonal unit cell of the mesoporous material and showed that the structure of mesoporous SBA-15 was retained during immobilization [31]. Furthermore, the lower angle in the XRD pattern of $\mathrm{Cu}(\mathrm{II})$-DiAmSar/SBA-15 was due to the development of a unit cell arising from the connection of the complex in SBA-15, and the lower intensity was due to a decrease in the mesoscopic order.

The TEM images of $\mathrm{Cu}(\mathrm{II})$-DiAmSar/SBA-15 are presented in Fig. 2(c) and (d) in the direction of the pore axis (Fig. 2(c)) and perpendicular to the pore axis of $\mathrm{Cu}(\mathrm{II})$-DiAmSar/SBA-15 (Fig. 2(d)). The TEM images of the supported complex confirmed the retaining of the cylindrical shape of the pores and the hexagonal arrays of uniform channels.

$\mathrm{N}_{2}$ adsorption-desorption isotherms and pore size distributions of the samples are depicted in Fig. 3(a). Both SBA-15 and $\mathrm{Cu}(\mathrm{II})$-DiAmSar/SBA-15 exhibited type IV isotherms with a small $\mathrm{H}_{1}$ hysteresis loop, showing that the
Table 1

Textural properties of SBA-15 and Cu(II)-DiAmSar/SBA-15.

\begin{tabular}{lccc}
\hline Material & $S_{\mathrm{BET}}{ }^{\mathrm{a}}\left(\mathrm{m}^{2} / \mathrm{g}\right)$ & $V_{\mathrm{BJH}}{ }^{\mathrm{b}}\left(\mathrm{cm}^{3} / \mathrm{g}\right)$ & $D_{\mathrm{BJH}^{\mathrm{c}}}(\mathrm{nm})$ \\
\hline SBA-15 & 532 & 0.600 & 6.24 \\
$\mathrm{Cu}(\mathrm{II})$-DiAmSar/SBA-15 & 317 & 0.560 & 6.10 \\
\hline
\end{tabular}

a Specific surface area.

bPore volume.

cPore diameter (calculated from the adsorption branch).

cage-like structure of SBA-15 was maintained after grafting with $\mathrm{Cu}(\mathrm{II})$-DiAmSar [32]. The textural parameters of the samples are collected in Table 1 . As can be seen, the surface area, pore diameter, and pore volume of $\mathrm{Cu}(\mathrm{II})$-DiAmSar/ SBA-15 decreased with the immobilization of $\mathrm{Cu}(\mathrm{II})$-DiAmSar inside the channels of SBA-15.

Table 2

Screening of the reaction conditions for the reaction of 1,2-phenylenediamine 8a and benzil 9a.

\begin{tabular}{lccccc} 
Entry & Solvent & $\begin{array}{c}\text { Catalyst } \\
\left(10^{-5} \mathrm{mmol}\right)\end{array}$ & $t /{ }^{\circ} \mathrm{C}$ & $\begin{array}{c}\text { Time } \\
(\mathrm{min})\end{array}$ & $\begin{array}{c}\text { Yield }^{\mathrm{a}} \\
(\%)\end{array}$ \\
\hline 1 & Free & 0 & $\mathrm{rt}$ & 320 & - \\
2 & Free & 8 & $\mathrm{rt}$ & 10 & 30 \\
3 & Free & 16 & $\mathrm{rt}$ & 10 & 30 \\
4 & Free & 0.8 & $\mathrm{rt}$ & 10 & 20 \\
5 & Free & 8 & 60 & 10 & 65 \\
$6^{\mathrm{b}}$ & Free & 8 & 100 & 10 & $99(98 \mathrm{c})$ \\
7 & $\mathrm{H} 2 \mathrm{O}$ & 8 & Reflux & 120 & 80 \\
8 & EtOH & 8 & Reflux & 100 & 85 \\
9 & DMF & 8 & 100 & 80 & 78 \\
10 & Toluene & 8 & Reflux & 160 & 85
\end{tabular}

Reaction conditions: 1,2-Phenylenediamine 8a (1 mmol, 1 equiv), benzil 9a (1.0 mmol, 1 equiv) and catalyst (0-0.00016 mmol based on $\mathrm{Cu}(\mathrm{II})$ ions or $0-0.05 \mathrm{~g}$ of $\mathrm{Cu}(\mathrm{II})-\mathrm{DiAmSar} / \mathrm{SBA}-15)$ were heated for an appropriate time in a solvent $(2 \mathrm{~mL})$ or solvent-free conditions.

a Based on GC yields.

b Optimum conditions.

c Isolated yield.
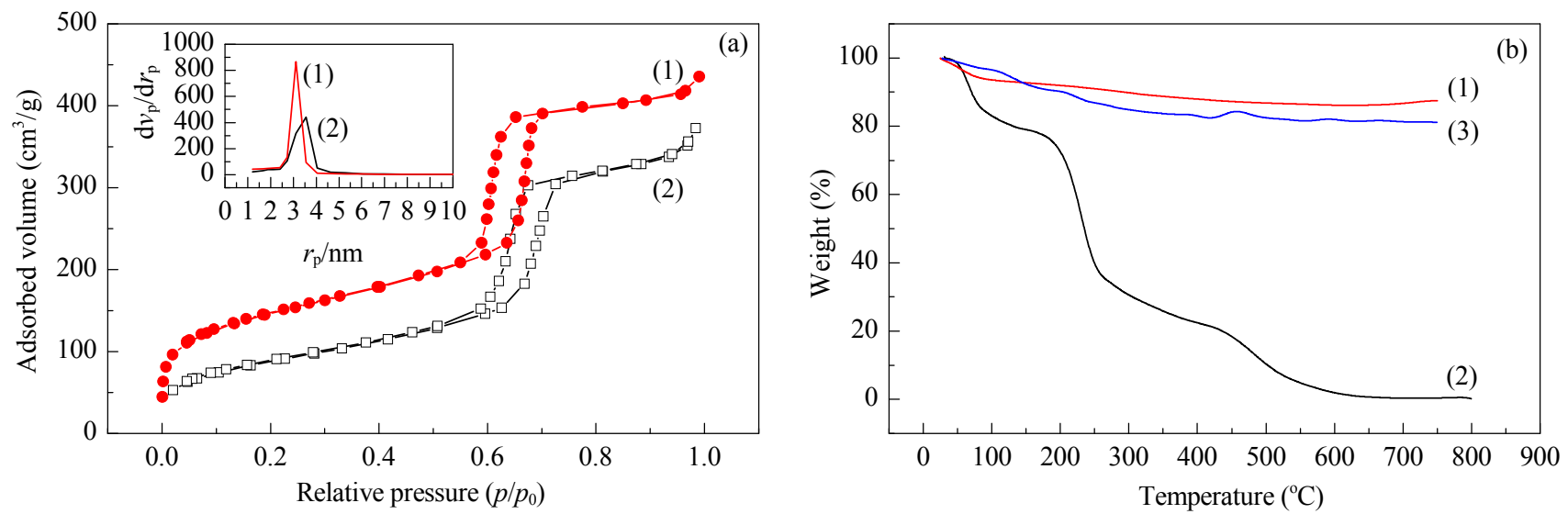

Fig. 3. (a) $\mathrm{N}_{2}$ adsorption isotherms and corresponding pore size distributions (inset) of SBA-15 (1) and Cu(II)-DiAmSar/SBA-15(2). (b) TGA curves of SBA-15(1), Cu(II)-DiAmSar/SBA-15(2), and DiAmSar (3). 
Figure 3(b) illustrates the TGA profiles of pure SBA-15 and Cu(II)-DiAmSar/SBA-15. Pure siliceous SBA-15 showed a mass loss below $100{ }^{\circ} \mathrm{C}$ due to the loss of physically adsorbed water from the surface of SBA-15. The thermogram of $\mathrm{Cu}(\mathrm{II})$-DiAmSar/SBA-15 showed weight losses at two temperatures: the weight loss at $100{ }^{\circ} \mathrm{C}$ was from dehydration and the weight loss between 200 and $700{ }^{\circ} \mathrm{C}$ was from the thermal decomposition of grafted $\mathrm{Cu}(\mathrm{II})$-DiAmSar moieties. These results confirmed the successful grafting of the $\mathrm{Cu}(\mathrm{II})$-DiAmSar complex on the SBA-15 surface. According to the TGA data, the grafting amount of DiAmSar on SBA-15 was 62 wt\% (based on the initial amount of DiAmSar used for the anchoring).

\subsection{Catalyst activity}

To test the activity of the catalyst, initially, the reaction between 1,2-phenylenediamine (8a) and benzil (9a) was selected as a model reaction to find the best reaction conditions (Table 2). In the first attempt, we examined the reaction at room temperature in the absence of the catalyst, which gave no

Table 3

Synthesis of 2,3-disubstituted quinoxalines catalyzed by $\mathrm{Cu}(\mathrm{II})$-DiAmSar/SBA-15.

\begin{tabular}{|c|c|c|c|c|c|c|}
\hline Entry & Diamine 8 & Diketone 9 & Product 10 & Yield (\%) & Time (min) & m.p. $\left({ }^{\circ} \mathrm{C}\right)$ (lit.) \\
\hline 1 & $8 a$ & & & 98 & 10 & $121-123$ (124 [33]) \\
\hline 2 & $8 a$ & & & 92 & 10 & $148-150(151-152.5$ [33]) \\
\hline 3 & $8 a$ & & & 99 & 5 & $133-134(135-137$ [33]) \\
\hline 4 & $8 a$ & & & 99 & 5 & $102-104(104-106[34])$ \\
\hline 5 & $8 b$ & 9a & & 88 & 30 & 183-185 (183 [34]) \\
\hline 6 & $8 b$ & 9d & & 99 & 5 & $130-132(131-133$ [35]) \\
\hline 7 & 8c & 9a & $10 \mathrm{~g}$ & 99 & 5 & $114-116(110-111[35])$ \\
\hline 8 & $8 c$ & $9 b$ & $10 \mathrm{~h}$ & 96 & 20 & $123-125$ (124-126 [35]) \\
\hline 9 & $8 c$ & 9d & $10 \mathrm{i}$ & 99 & 5 & $90-92$ (92-94 [35]) \\
\hline
\end{tabular}

Reaction conditions: 1,2-Phenylenediamine 8a (1 mmol, 1 equiv), benzil 9a (1.0 mmol, 1 equiv) and catalyst (0.005 g of Cu(II)-DiAmSar/SBA-15 or $8 \times 10^{-5} \mathrm{mmol}$ based on $\mathrm{Cu}(\mathrm{II})$ ions) were heated at $100^{\circ} \mathrm{C}$ under solvent-free conditions. 
yield of product. Although using dimethylformamide and ethanol as solvent gave reasonable yields (Table 2, entries 8 and 9), the best yield was obtained under the solvent-free condition at $100{ }^{\circ} \mathrm{C}$ and in the presence of $8 \times 10^{-5} \mathrm{mmol}$ of the catalyst (Table 2 , entry 6).

With the optimized conditions in hand, the generality of the reaction was evaluated by using various diamines and 1,2-diketones (Tables 3 and 4). Most of the substrates gave good to excellent yields in short reaction times.

The reactivity of aromatic and hetero-aromatic diamines is generally dominated by electronic effects. In general, aromatic and hetero-aromatic diamines with electron-withdrawing groups (EWG) react more slowly when compared to other diamines. For example, the condensation reaction of less electron-rich diamines, including substituted 1,2- phenylenediamines bearing EWG (Table 3, entry 5) and diaminopyridines (Table 4, entries 1-9), was slower and gave lower yields. The reactivity of the aliphatic diamines with various 1,2-diketones was good (Table 4, entries 10-12 and 14). New quinoxaline derivatives were synthesized through the reactions of aliphatic diamine (1,2-diaminopropanean $\mathbf{8 h}$ ) with acenaphthenequinone 9e and phenanthrenequinone 9f (Table 4, entries 13 and 14) in high yields and at lower temperature than the optimized conditions. The initial products of the aliphatic diamines can undergo a further oxidation step to give fully aromatic and stable final products (Table 4, entries 10, 11, and 13). For example, the reaction of aliphatic diamine $\mathbf{8 h}$ and diketone 9f (Table 4, entry 14) gave directly the final product 10w (fully aromatic) via a one-pot protocol. The presence of a singlet peak at $2.84 \mathrm{ppm}$ for the $\mathrm{CH}_{3}$ group and another singlet

Table 4

Synthesis of pyridopyrazine and pyrazine derivatives in the presence of a catalytic amount of Cu(II)-DiAmSar/SBA-15.

\begin{tabular}{|c|c|c|c|c|c|c|c|c|c|c|c|c|c|}
\hline $\begin{array}{l}\text { En- } \\
\text { try } \\
\end{array}$ & $\begin{array}{c}\text { Diamine } \\
\mathbf{8} \\
\end{array}$ & $\begin{array}{c}\text { Diketone } \\
\mathbf{9} \\
\end{array}$ & Product $\mathbf{1 0}$ & $\begin{array}{l}\text { Yield } \\
(\%) \\
\end{array}$ & $\begin{array}{l}\text { Time } \\
(\mathrm{min})\end{array}$ & $\begin{array}{c}\text { m.p. }\left({ }^{\circ} \mathrm{C}\right) \\
\text { (lit.) }\end{array}$ & $\begin{array}{l}\text { En- } \\
\text { try }\end{array}$ & $\begin{array}{c}\text { Diamine } \\
\mathbf{8} \\
\end{array}$ & $\begin{array}{c}\text { Diketone } \\
\mathbf{9} \\
\end{array}$ & Product 10 & $\begin{array}{c}\text { Yield } \\
(\%) \\
\end{array}$ & $\begin{array}{l}\text { Time } \\
\text { (min) }\end{array}$ & $\begin{array}{c}\text { m.p. }\left({ }^{\circ} \mathrm{C}\right) \\
\text { (lit.) }\end{array}$ \\
\hline 1 & 8d & $9 a$ & 10j & 80 & 45 & $\begin{array}{c}141-143 \\
(142-143 \\
[35])\end{array}$ & 8 & $8 e$ & 9f & $10 q$ & 80 & 50 & $\begin{array}{c}217-218 \\
(216-218 \\
[20])\end{array}$ \\
\hline 2 & 8d & $9 c$ & & 85 & 45 & $\begin{array}{c}142-144 \\
(140-142 \\
[20])\end{array}$ & 9 & $8 e$ & $9 e$ & $10 \mathrm{r}$ & 80 & 50 & $\begin{array}{c}246-248 \\
(245-247 \\
[20])\end{array}$ \\
\hline 3 & 8d & $9 b$ & $10 \mathrm{i}$ & 77 & 90 & $\begin{array}{c}137-139 \\
(139-140 \\
[35])\end{array}$ & 10 & $\begin{array}{l}\mathrm{NH}_{2} \\
\mathbf{8 f}\end{array}$ & $9 a$ & & 99 & 5 & $\begin{array}{c}154-156 \\
(160-161 \\
[34])\end{array}$ \\
\hline 4 & 8d & $9 e$ & $10 \mathrm{~m}$ & 88 & 60 & $\begin{array}{c}222-224 \\
(225-227 \\
[20])\end{array}$ & 11 & $8 f$ & $9 e$ & $10 t$ & 99 & 5 & $\begin{array}{c}162-164 \\
(165-167 \\
[20])\end{array}$ \\
\hline 5 & $8 \mathbf{e}$ & $9 b$ & & 74 & 90 & $\begin{array}{c}145-147 \\
(147-148 \\
[37])\end{array}$ & 12 & 8g & 9d & $10 u$ & 95 & 5 & $\begin{array}{c}160-162 \\
(162-164 \\
[20])\end{array}$ \\
\hline 6 & $8 e$ & $9 c$ & 10 & 78 & 50 & $\begin{array}{c}133-135 \\
(132-134 \\
[20])\end{array}$ & 13 & $\begin{array}{l}\mathrm{NH}_{2} \\
\mathbf{8 h}\end{array}$ & $9 e$ & $10 v$ & 98 & 5 & $73-75$ \\
\hline 7 & $8 e$ & $9 a$ & $10 p$ & 79 & 60 & $\begin{array}{c}170-172 \\
(173-174 \\
[36])\end{array}$ & 14 & $8 h$ & 9f & $10 w$ & 81 & 5 & $121-123$ \\
\hline
\end{tabular}

Reaction conditions: 1,2-Phenylenediamine 8a (1 mmol, 1 equiv), benzil 9a (1.0 mmol, 1 equiv) and catalyst (0.005 g of Cu(II)-DiAmSar/SBA-15 or $8 \times 10^{-5} \mathrm{mmol}$ based on $\mathrm{Cu}(\mathrm{II})$ ions) were heated at $100^{\circ} \mathrm{C}$ under solvent-free conditions. 
peak at $8.77 \mathrm{ppm}$ for the $\mathrm{CH}$ group (in pyrazine ring, compound 10w) in the ${ }^{1} \mathrm{H}$ NMR spectrum demonstrated the synthesis of this derivative. To get more details about the intermediate, we investigated the corresponding reaction for compound $10 \mathrm{w}$ (unoxidized compound). The reaction was quenched at half its completion time, and the ${ }^{1} \mathrm{H}$ NMR of the crude mixture was analyzed (Fig. 4).

The appearance of a doublet peak at $1.46 \mathrm{ppm}$ for $\mathrm{CH}_{3}$ (peak b) and $\mathrm{CH}_{2}$ diastereotopic hydrogen peaks ( $\mathrm{d}$ and e peaks) at 3.31 and 3.99 ppm (Fig. 4, compound 10x) demonstrated the presence of an unoxidized intermediate (compound 10x) in the reaction mixture. Although products obtained from aliphatic diamines can be fully aromatic compounds, this was not a general rule in our protocol. For instance, compound $10 \mathbf{v}$ (Table 4, entry 13) was not oxidized during the reaction. This was demonstrated by the presence of the doublet peaks of $\mathrm{CH}_{2}$ (diastereotopic hydrogen) at 3.54 and $4.05 \mathrm{ppm}$, multiplet peaks of $\mathrm{CH}$ hydrogen atom (the $\mathrm{H}$ on the carbon chiral center) at $3.88 \mathrm{ppm}$, and doublet peaks of the $\mathrm{CH}_{3}$ hydrogen group at $1.46 \mathrm{ppm}$ in ${ }^{1} \mathrm{H}$ NMR spectrum (compound 10v).

Some of the reactions in Table 3 were fast enough that they were completed in shorter reaction times than that of the optimized conditions. Furthermore, the reactivity of 1,2diketones with electron-donating groups was slower with different diamines, for both the time and yield of the reactions (Table 4, entries 3 and 5).

The reusability of the catalyst was examined by repeating the model reaction (compound 10a) under the optimized conditions. After the first reaction with $98 \%$ yield, the catalyst

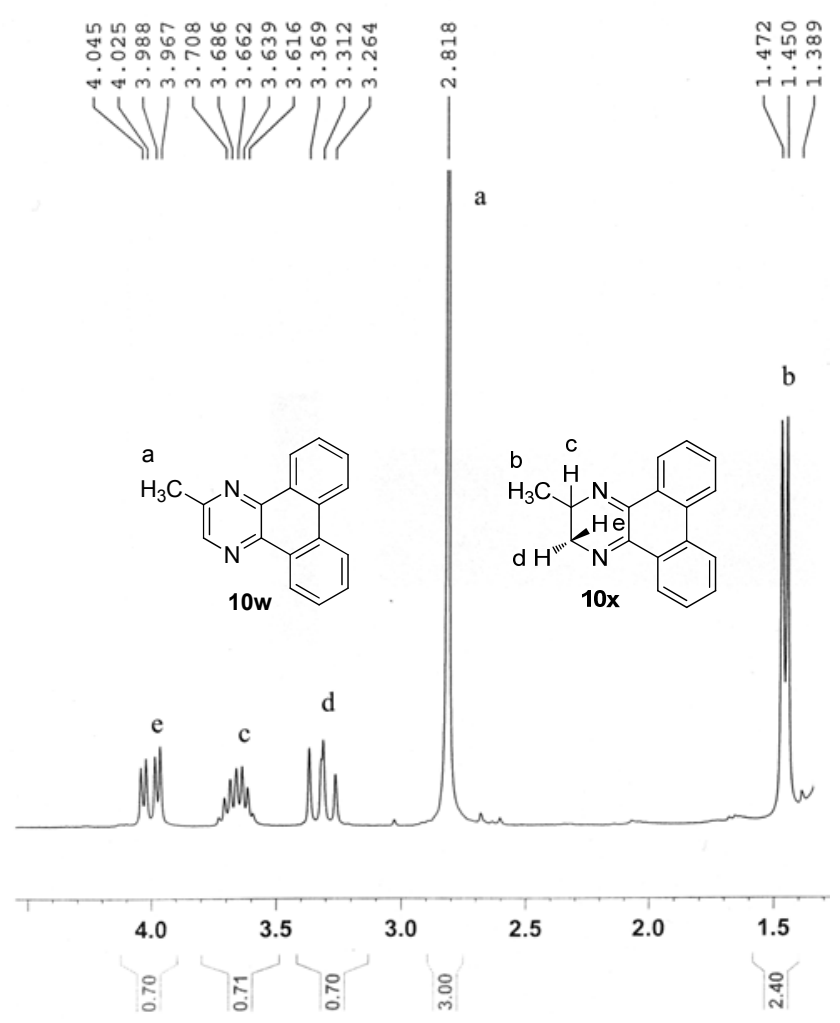

Fig. 4. ${ }^{1} \mathrm{H}$ NMR spectrum of a sample from the crude reaction mixture giving compound 10w.
Table 5

Reuse of the catalyst for the synthesis of 2,3-diphenylquinoxaline 10a.

\begin{tabular}{lccccccc}
\hline Run & 1 & 2 & 3 & 4 & 5 & 6 & 7 \\
\hline Isolated yield (\%) & 99 & 99 & 99 & 98 & 97 & 97 & 96 \\
\hline
\end{tabular}

Table 6

Comparison of our results with some previously reported data for the synthesis of compound 10a.

\begin{tabular}{lccrrc}
\hline Method & Solvent & $t /{ }^{\circ} \mathrm{C}$ & $\begin{array}{r}\text { Time } \\
(\mathrm{min})\end{array}$ & $\begin{array}{r}\text { Yield } \\
(\%)\end{array}$ & Ref. \\
\hline $\mathrm{Zr}(\mathrm{DS})_{4}$ & $\mathrm{H}_{2} \mathrm{O}$ & $\mathrm{rt}$ & 30 & 94 & {$[37]$} \\
$\mathrm{MnCl}_{2}$ & $\mathrm{EtOH}$ & $\mathrm{rt}$ & 17 & 94 & {$[38]$} \\
Pd(II)-Schiff base/SBA-15 & $\mathrm{H}_{2} \mathrm{O}$ & 100 & 30 & 99 & {$[20]$} \\
& $\mathrm{HFIP}$ & $\mathrm{rt}$ & 60 & 95 & {$[39]$} \\
Mont K-10 (10 mol\%) & $\mathrm{H}_{2} \mathrm{O}$ & $\mathrm{rt}$ & 150 & 100 & {$[40]$} \\
Silica sulfuric acid & $\mathrm{EtOH}$ & $\mathrm{rt}$ & 15 & 98 & {$[41]$} \\
Sulfamic acid & $\mathrm{MeOH}$ & 25 & 5 & 100 & {$[42]$} \\
In (5 nmol)/InCl 3 & $\mathrm{MeOH}$ & $\mathrm{Reflux}$ & 30 & 85 & {$[43]$} \\
Fe(III)-Schiff base/SBA-15 & Water & Reflux & 120 & 99 & {$[22]$} \\
Cu(II)-DiAmSar/SBA-15 & Solvent- & 100 & 5 & 99 & This \\
& free & & & & work \\
\hline
\end{tabular}

was first filtered, then washed with hot ethanol, and dried at 80 ${ }^{\circ} \mathrm{C}$ for $60 \mathrm{~min}$. The recovered catalyst was used in another reaction, and we found that the $\mathrm{Cu}(\mathrm{II})$-DiAmSar/SBA-15 catalyst can be recycled up to six times without any loss of activity (Table 5).

We compared some previously reported data for the synthesis of 10a (Table 3, entry 1) with our protocol (Table 6). Our results were good in comparison to previously reported data in terms of yields, environment, and reaction times.

\section{Conclusions}

We synthesized and characterized a new active heterogeneous mesoporous catalyst of $\mathrm{Cu}(\mathrm{II})$-DiAmSar complex grafted onto SBA-15. The catalyst was active for the synthesis of nitrogen containing pyrazine-based heterocycles, including pyrazine, pyrido[2,3- $b]$ pyrazine, and quinoxaline derivatives, with good to excellent yields under mild conditions.

\section{References}

[1] Yadav J S, Reddy B V S, Premalatha K, Shankar K S. Synthesis, 2008: 3787

[2] He W, Myers M R, Hanney B, Spada A P, Bilder G, Galzcinski H, Amin D, Needle S, Page K, Jayyosi Z, Perrone M H. Bioorg Med Chem Lett, 2003, 13: 3097

[3] Escobar-Chavez J J, Merino V, Lopez-Cervantes M, Rodriguez-Cruz I M, Quintanar-Guerrero D, Ganem-Quintanar A. Curr Drug Discov Technol, 2009, 6: 171

[4] McLaughlin M A, Chiou G C Y.J Ocul Pharmacol, 1985, 1: 101

[5] Hugo W B, Stretton R G. Nature, 1964, 202: 1217

[6] Wu S H, Mou C Y, Lin H P. Chem Soc Rev, 2013, 42: 3862

[7] Conley M P, Copéret C, Thieuleux C. ACS Catal, 2014, 4: 1458

[8] Xie W L, Qi C.J Agr Food Chem, 2014, 62: 3348

[9] Xie W L, Hu L B, Yang X L. Ind Eng Chem Res, 2015, 54: 1505

[10] Xie W L, Zhao L L. Energy Convers Manage, 2014, 79: 34

[11] Meynen V, Cool P, Vansant E F. Microporous Mesoporous Mater, 2009, 125: 170 


\section{Graphical Abstract}

Chin. J. Catal., 2015, 36: 1379-1386 doi: 10.1016/S1872-2067(15)60845-2

Efficient solvent-free synthesis of pyridopyrazine and quinoxaline derivatives using copper-DiAmSar complex anchored on SBA-15 as a reusable catalyst

Marzieh Mohammadi, Ghasem Rezanejade Bardajee*, Nader Noroozi Pesyan

Urmia University, Iran; Payame Noor University, Iran

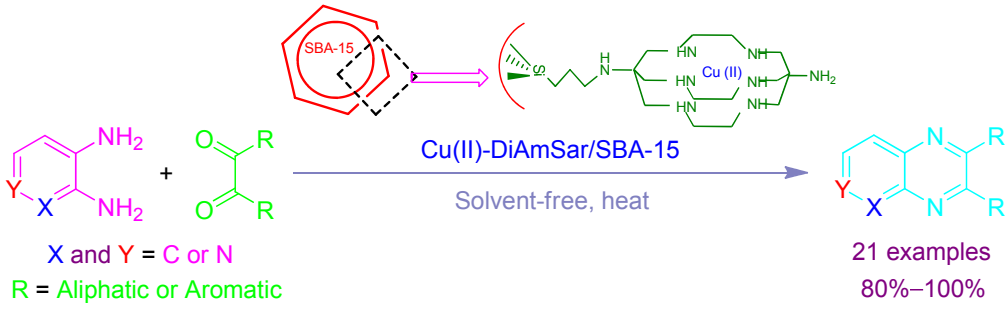

A silica-based mesoporous organic-inorganic hybrid catalyst was synthesized by anchoring Cu(II)-DiAmSar on SBA-15, which gave high activity for the synthesise of pyridopyrazine and quinoxaline derivatives under solvent-free conditions.

[12] Liu J, Liu Y, Yang W, Guo H, Zhang H Z, Tang Z H, Fang F. Mater Lett, 2014, 128: 15

[13] Shakeri M, Gebbink R J M K, de Jongh P E, de Jong K P. Microporous Mesoporous Mater, 2013, 170: 340

[14] Walcarius A, Mercier L.J Mater Chem, 2010, 20: 4478

[15] Yang Y, Zhang Y, Hao S J, Kan Q B. Chem Eng J, 2011, 171: 1356

[16] Coperet C, Chabanas M, Saint-Arroman R P, Basset J M. Angew Chem Int Ed, 2003, 42: 156

[17] Zou X C, Shi K Y, Wang C. Chin J Catal (邹晓川, 石开云, 王存. 催化 学报), 2014, 35: 1446

[18] Zhu X C, Shen R W, Zhang L X. Chin J Catal (朱学成, 沈如伟, 张利 雄. 催化学报), 2014, 35: 1716

[19] Malakooti R, Bardajee G R, Hadizadeh S, Atashin H, Khanjari H. Transit Metal Chem, 2014, 39: 47

[20] Motamedi R, Bardajee G R, Shakeri S. Heterocycl Commun, 2014, 20: 181

[21] Malakooti R, Bardajee G R, Mahmoudi H, Kakavand N. Catal Lett, 2013, 143: 853

[22] Bardajee G R, Malakooti R, Abtin I, Atashin H. Microporous Mesoporous Mater, 2013, 169: 67

[23] Bardajee G R, Malakooti R, Jami F, Parsaei Z, Atashin H. Catal Commun, 2012, 27: 49

[24] Mohammadi M, Bardajee G R, Pesyan N N. RSC Adv, 2014, 4: 62888

[25] Qin C J, James L, Chartres J D, Alcock L J, Davis K J, Willis A C, Sargeson A M, Bernhardt P V, Ralph S F. Inorg Chem, 2011, 50: 9131

[26] Geue R J, Hambley T W, Harrowfield J M, Sargeson A M, Snow M R. J Am Chem Soc, 1984, 106: 5478

[27] Di Bartolo N, Sargeson A M, Smith S V. Org Biomol Chem, 2006, 4:
3350

[28] Bell C A, Bernhardt P V, Gahan L R, Martinez M, Monteiro M J, Rodriguez C, Sharrad C A. Chem Eur J, 2010, 16: 3166

[29] Cai H, Fissekis J, Conti P S. Dalton Trans, 2009: 5395

[30] Hilderbrand S A, Weissleder R. Curr Opin Chem Biol, 2010, 14: 71

[31] Pathak K, Ahmad I, Abdi S H R, Kureshy R I, Khan N H, Jasra R V. J Mol Catal A, 2008, 280: 106

[32] Zhao D Y, Huo Q S, Feng J L, Chmelka B F, Stucky G D. J Am Chem Soc, 1998, 120: 6024

[33] Heravi M M, Tehrani M H, Bakhtiari K, Oskooie H A. Catal Commun, 2007, 8: 1341

[34] Darabi H R, Mohandessi S, Aghapoor K, Mohsenzadeh F. Catal Commun, 2007, 8: 389

[35] Aghapoor K, Darabi H R, Mohsenzadeh F, Balavar Y, Daneshyar H. Transit Metal Chem, 2010, 35: 49

[36] Antoine M, Czech M, Gerlach M, Günther E, Schuster T, Marchand P. Synthesis, 2011: 794

[37] Hasaninejad A, Zare A, Zolfigol M A, Shekouhy M. Synthetic Commun, 2009, 39: 569

[38] Heravi M M, Bakhtiari K, Oskooie H A, Taheri S. Heteroat Chem, 2008, 19: 218

[39] Khaksar S, Rostamnezhad F. Bull Korean Chem Soc, 2012, 33: 2581

[40] Huang T K, Wang R, Shi L, Lu X X. Catal Commun, 2008, 9: 1143

[41] Ahmad S, Ali M. Chin J Chem, 2007, 25: 818

[42] Darabi H R, Mohandessi S, Aghapoor K, Mohsenzadeh F. Catal Commun, 2007, 8: 389

[43] Go A, Lee G, Kim J, Bae S, Lee B M, Kim B H. Tetrahedron, 2015, 71: 1215 